I Universidade de São Paulo (USP), Departamento de Sociologia,

São Paulo, SP, Brasil

waizbort@usp.br

https://orcid.org/oooo-0002-9789-9758

Leopoldo Waizbort ${ }^{\prime}$

\title{
CADA UM POR SI E NENHUM POR TODOS. ELEMENTOS DA COVARIAÇÃO NOS DOMÍNIOS DE ESTRUTURA SOCIAL E SEMÂNTICA
}

Leitores podem experimentar a teoria luhmanniana como um beco sem saída, com sua terminologia emaranhada, própria e difícil, seu desenho complexo, seu humor cifrado. Mas não valeria a pena considerá-la uma saída do beco ${ }^{\text {I }}$ Onde se poderia, pois, encontrar um mapa, quiçá uma pista, para escapar desse labirinto ou - quem sabe? - para nunca mais querer sair dele?²

Niklas Luhmann (1927-I998) publicou, a partir de I980, uma série de estudos sob a rubrica "estrutura social e semântica" que, hoje, contabiliza seis volumes e reúne 26 estudos. ${ }^{3}$ Eles oferecem entradas e saídas da teoria luhmanniana, algo distintas dos escritos dedicados à construção do conceito e ao desenho da teoria. São estudos "históricos", "empíricos", que permitem concretizar de outra maneira tanto o conceito como a teoria, em uma espécie de percurso inverso, mostrando pelo avesso a teoria e o linguajar complexos em ação.

Trata-se de esforço muito singular de articular teoria e história, em geral pouco reconhecido pela sociologia, uma vez que nunca se ouve falar de Luhmann quando o assunto é sociologia histórica. Entretanto, é disso que se trata, e o próprio Luhmann não deixou de assinalar as dificuldades e inconsistências com as quais o vínculo de teoria e história, tão decisivo para a sociologia, mas não somente para ela, amiúde se encontra (cf. Luhmann, I986: I-3; Luhmann, I980a; Luhmann, 2008c)

Não obstante, o esforço na dimensão histórica tem sua razão de ser. A teoria dos sistemas sociais, tal como elaborada por Luhmann ao longo das décadas de I960 a I990, tem no problema da diferenciação social um de seus 
fundamentos (ao lado das questões referentes à comunicação, à evolução e à autodescrição). Correlacionada ao processo histórico de diferenciação social há uma transformação semântica - do conjunto dos significados operantes na sociedade (ou, mais precisamente, nos distintos sistemas sociais parciais) e do modo como eles se concretizam em comunicações e na produção e reprodução de sentido -, que Luhmann procura historiar. Ou seja, procura identificar, no interior de problemas e contextos específicos, como a passagem da sociedade diferenciada por estratos para a sociedade diferenciada funcionalmente implicou - gerou, modelou, desenvolveu, aplicou - transformações semânticas: uma nova semântica do amor, da distribuição, do indivíduo, do Estado, da família, da religião, da propriedade, da educação, da classe, da moral, e muitas outras mais, para todos os domínios nos quais operam sistemas sociais que se diferenciam funcionalmente. Por semântica entende-se agora como se concebe, como se pensa, como se compreende, como se classifica, como se codifica etc., em suma, como se produz e assenta sentido (sem o qual não há comunicação, a operação basilar dos sistemas sociais), e importa compreender como isso se altera com a passagem da diferenciação estratificatória (a sociedade da "Velha Europa", como diz Luhmann) para a diferenciação funcional (a sociedade moderna). Observando ao revés, pode-se então caracterizar a sociedade moderna, funcionalmente diferenciada, via as transformações semânticas que ela consuma - e necessita imperativamente, para continuar existindo, pois depende de sentido, sem o qual as comunicações, que são as operações decisivas dos sistemas sociais, não se completam. Por essa razão, Luhmann (I992: I08) também afirmou que a semântica, ou o aparato semântico, constitui uma espécie de "estrutura da autopoiesis da comunicação", pois sem ela a autopoiesis não se realiza. Donde se aquilata a centralidade do problema.

Como indicam título e rubrica que enfeixa o conjunto de estudos, as transformações semânticas estão correlacionadas às transformações na estrutura social, sem que com isso se pretenda estabelecer causalidades. ${ }^{4}$ Isso evidencia a mencionada questão da passagem da sociedade diferenciada por estratos para a sociedade diferenciada por funções; a passagem para a sociedade moderna é, portanto, o grande tema que aflora desse conjunto de estudos. Desenvolve-se aí um plano comparativo bastante rico, seja porque, de um lado, obtemos visada comparativa para as "velha" e "nova" sociedades; seja porque, de outro lado, na sociedade moderna a diferenciação funcional por vezes propicia a recorrência de uma "mesma" semântica em distintos subsistemas (por exemplo, no direito e na economia), oferecendo não um substrato comum, mas uma complexa teia de interconexões e irritações em sistemas que - como preconiza a teoria dos sistemas sociais de Luhmann - são fechados operacionalmente (cf. Luhmann, I994; I 997) Ou seja, o sistema do direito tem em seu ambiente o sistema da economia, e vice-versa; portanto, ocorrência de uma semântica similar em ambos produz sentidos distintos em cada um deles. Bas- 
taria atentar para as diferenças finas entre a utilização de uma semântica "reincidente" ou "comum" em distintos sistemas parciais para já termos uma via de rico esclarecimento sociológico acerca das complexas dinâmicas dos diferentes sistemas na sociedade moderna. Essa mesma questão também pode ser abordada sob a forma dos acoplamentos estruturais.

A sociedade diferenciada funcionalmente tem sua complexidade intensificada, a contingência de suas operações torna-se, assim, ainda mais ampla, e a isso "responde" a semântica, oferecendo "sentidos". ${ }^{5}$ Luhmann (I980a: I9) assim define a questão:

Queremos denominar semântica de uma sociedade a totalidade de formas de uma sociedade utilizáveis para essa função [a saber: a tipificação do sentido, LW] e denominamos seu aparato semântico o seu estoque de regras de elaboração de sentido já disponibilizadas. Consequentemente, compreendemos como semântica o sentido generalizado no mais alto grau, disponível de modo relativamente independente da situação (v. tb. Luhmann i98r: 7).

E como isso não deixa de se alterar ao longo do tempo, dado que sistemas sociais são extremamente dinâmicos, Luhmann também fala de "evolução de ideias", pois que a transformação ao longo do tempo remete à sua teoria da evolução (cf. nota 4).

A semântica situa-se, ademais, como uma espécie de resultante da diferenciação e da complexidade. Diferenciação é diferenciação de sistema e ambiente (que se reproduz então internamente ao sistema); complexidade a resultante de processos intrassistêmicos, envolvendo elementos (do sistema) e relações (que se estabelecem internamente entre elementos), que exigem seleção.

Nas palavras de Luhmann (I980a: 35): "Se é correto que a complexidade coloca um sistema sob pressão de seleção e se é correto que o sentido organiza a seletividade, é preciso então supor que a complexidade que varia em função da evolução cria para si correlatos semânticos nas dimensões de sentido singulares". Temos, assim, evolução de ideias, que vão se modificando e consequentemente oferecendo novos e diferentes abrigos a sentidos, ou seja, seleções, possibilitando com isso redução de complexidade, e, portanto, operação do sistema: sua existência e reprodução/manutenção. As operações do sistema, por sua vez, estão assentadas na autopoiesis, no fechamento operacional e na autorreferência dos sistemas sociais. E, como se viu, a semântica é uma estrutura da autopoiesis.

Entende-se, assim, de que modo a teoria dos sistemas sociais de Luhmann se articula nesse conjunto de problematizações, o que nos faculta abordar essa teoria por outra via, digamos a de uma "história dos conceitos", dando carne e osso aos problemas e temas que na exposição da teoria enquanto tal aparecem muita vez de modo bastante abstrato - como, por exemplo, em Sistemas sociais. (Luhmann, I994; 2002) Esse vínculo de teoria e história é simul- 
taneamente muito abstrato e muito concreto. Sua abstração mostra-se na teoria propriamente, como já se pode ver. E sua concretude realiza-se na produção de sentido, ou seja, nas comunicações que ocorrem sem parar no âmbito dos diversos sistemas. Não estamos falando de conceitos abstratos, mas sim de mecanismos que são utilizados o tempo todo pela sociedade para dar sentido às comunicações. Destarte, ao investigar o nexo de estrutura social e semântica, encontramos ainda uma via para adentrar a operação dos distintos subsistemas da sociedade, como a arte, a economia, o direito, a ciência, a religião e assim por diante, uma vez que eles todos, em suas operações comunicativas, visam a sentido, sentido esse guarnecido pela semântica social. Que, como se disse, oferece e opera uma tipificação.

Com sua ironia característica, Luhmann reservou a expressão "Velha Europa" para designar a sociedade europeia do passado, caracterizada pela forma de diferenciação por estratos, ou seja, a sociedade estamental, emblematicamente a sociedade do Antigo Regime. No contexto de sua teoria dos sistemas sociais, a forma de diferenciação por estratos caracteriza uma modalidade de sociedade que, em termos gerais, predominou no âmbito europeu até o século XVIII, quando começou a ser substituída por uma forma de sociedade na qual a diferenciação assumiu outra forma, de caráter funcional.

Essa passagem da forma de diferenciação por estratos para a forma de diferenciação por funções detém especial importância, dado que assinala a transição para o mundo em que vivemos, a sociedade moderna. Características decisivas do mundo moderno, e não mais da "Velha Europa", residem na semântica que orienta os sentidos possíveis das comunicações que constituem os sistemas sociais, agora funcionalmente diferenciados - a sociedade como sistema global (Luhmann, I999; 2009: 62-88; 20I7b: 44ISs.) e os diversos subsistemas sociais.

Isso nos permite ponderar em que medida os estudos de Luhmann que investigam a correlação de estrutura social e semântica possuem duplo ponto de partida. Por um lado, o desafio de constituir uma teoria dos sistemas e em especial dos sistemas sociais, nos quais o sentido ocupa uma posição decisiva (cf. Luhmann, I994). Por outro lado, a constatação da ruína da Velha Europa, com sua diferenciação social de caráter hierárquico, a estrutura social estamental. Essa dupla base indica um terceiro aspecto, o nexo de teoria e história, e o esforço é precisamente esse. Por essa razão, as investigações sobre a correlação possuem uma posição estratégica no interior do projeto luhmanniano, definindo um campo de investigação algo distinto da construção da teoria, assim como dos inúmeros estudos de Luhmann a respeito de subsistemas específicos - a educação, a economia, a política, a família, a saúde, a ciência, o direito e assim por diante.

Luhmann (I980a: I5) argumenta que pelo menos desde o Iluminismo, que acompanhou mais ou menos sincronicamente a ruína da "Velha Europa", o nexo de ideias e contexto é tema de reflexão; o mesmo problema se reapre- 
senta na ideia de uma consciência histórica que opera de modo autorreflexivo, tal como tematizada pelo menos desde Hegel; e é sobretudo na especialidade sociológica da "sociologia do conhecimento" que "a questão acerca da correlação ou covariação de estoques de conhecimento e estruturas sociais" se tornou um objeto específico de investigação, com enormes exigências para a teoria.

No entender de nosso autor, especialmente a moderna teoria dos sistemas estaria guarnecida para enfrentar esse desafio, pelo fato de conter uma teoria da evolução e uma teoria da comunicação. Assim, tal correlação ou covariação poderia ser mais bem compreendida, ou ao menos circunscrita, se amparada por uma teoria da evolução social - razão pela qual Luhmann (I997: 536-556; 2008b; I980a: I9) também utiliza a expressão "evolução das ideias" -, teoria essa assentada em uma teoria da diferenciação social. Luhmann (I g8oa: I7) desenvolve essa questão do seguinte modo:

o patrimônio de ideias não pode variar aleatoriamente com relação à sociedade que o utiliza. Com isso, o problema teórico desloca-se para a questão de como a estrutura social limita a aleatoriedade. Para obter uma resposta necessitamos de uma teoria das formas e consequências da diferenciação social.

É nesse ponto que a teoria da diferenciação dos sistemas sociais entra em cena. Diferenciação é sempre diferenciação de sistema e ambiente; portanto, se falamos de modalidades de diferenciação, falamos de diferentes tipos de constituição da diferença sistema/ambiente. Quando se diz, portanto, diferenciação segmentar ou diferença centro/periferia, ou diferenciação por estratos, ou diferenciação funcional - que são as modalidades apontadas por Luhmann -, isso significa que diferenças sistema/ambiente são estabelecidas de diferentes maneiras, constituindo sistemas sociais que operam de modos próprios e distintos.

No processo de evolução das sociedades, pode ocorrer que um aumento da complexidade do sistema conduza a uma alteração de seu modo de diferenciação. Trata-se, evidentemente, de um processo bastante complexo: a emergência de uma nova ordem. Que sempre assume a forma de um primado, ou seja, ela não impede que formas anteriores de diferenciação (que possibilitam menor complexidade, menos seleções, menos operações) continuem existindo em domínios específicos (sem esquecer que "desenvolvimentos regressivos" são sempre possíveis, dada a contingência). Mas a forma dominante das comunicações, das operações do sistema, depende da forma de diferenciação.

Luhmann indica que, no curso de desenvolvimento das sociedades, quatro formas distintas de diferenciação definem (até agora) a estrutura dos sistemas sociais. O tema é vasto e complexo e por essa razão reproduzo uma apresentação bem resumida pelo próprio Luhmann (cf. I997: cap. 4; 2008e: cap. I6).

(I) Diferenciação segmentar, sob o ponto de vista da igualdade dos sistemas sociais parciais, que se distinguem em virtude da ancestralidade ou da comunidade de morada, ou com uma combinação dos dois critérios. 
(2) Diferenciação segundo centro e periferia. Nesse caso, é permitida uma ocorrência de desigualdade, que ao mesmo tempo transcende o princípio da segmentação e, portanto, prevê nos dois lados da nova forma uma pluralidade de segmentos (domicílios). [...]

(3) Diferenciação estratificatória, sob o ponto de vista da desigualdade segundo status dos sistemas parciais. Essa forma tem igualmente sua estrutura básica em uma distinção de dois lados, a saber, nobreza e povo comum. Mas ela seria, nessa forma, relativamente instável, pois que facilmente invertível. Hierarquias estáveis como o sistema de castas indiano ou a ordem estamental da Idade Média tardia, por mais artificiais que sejam, constituem pelo menos três planos, para criar a impressão de estabilidade.

(4) Diferenciação funcional, sob o ponto de vista tanto da desigualdade quanto da igualdade dos sistemas parciais. Sistemas funcionais são, em sua desigualdade, iguais. Nisso radica uma renúncia a todas as diretrizes da sociedade como um todo para as relações entre eles. Agora não ocorre nem uma única desigualdade, como no caso de centro e periferia, nem uma forma da sociedade como um todo para o relacionamento transitivo de todas as desigualdades, com a evitação de relações circulares de retorno (feed-back). Justamente essas relações são então absolutamente típicas e normais (Luhmann, I997: 6I3). ${ }^{6}$

O problema que nos interessa situa-se na passagem, no âmbito do processo de variação evolutiva da sociedade, da diferenção estratificatória para a diferenciação funcional. Embora não se trate de um processo unívoco, e sua temporalidade seja estendida, multiforme e variada, foi por volta do século XVIII que a complexidade social atingiu níveis insustentáveis para a diferenciação estratificatória, possibilitando e exigindo a emergência da forma de diferenciação funcional. Temos, então, progressivamente um primado da diferenciação funcional, porque, como se disse, a temporalidade complexa dos processos em curso possibilita sincronias e assincronias variadas entre os diferentes sistemas que se diferenciam; além disso, empiricamente sempre podemos contar com situações em que, por exemplo, elementos de estratificação se sobreponham a elementos funcionais, e assim por diante - o que abre uma rica frente de investigação.

Os estudos de Luhmann acerca de estrutura social e semântica situamse exatamente nesse ponto, procurando mostrar como, na emergência de distintos sistemas parciais (ou subsistemas) da sociedade, ocorrem processos de transformação semântica com vistas a possibilitar sentido nessa situação alterada ou em mudança. Ou ainda: a transformação exige um novo compêndio de estruturas semânticas, capazes de dar sentido às comunicações gestadas no interior dos sistemas parciais que se estabelecem - e que para se estabelecer necessitam de uma semântica que possibilite sentido nas comunicações que os constituem enquanto sistemas sociais, não sendo essa circularidade casual, mas características de processos de emergência e da dinâmica dos sistemas sociais. Em termos cronológicos, esse processo é investigado por Luhmann em 
recortes temporais variados, definidos em função do problema e do sistema parcial em exame, ou seja, do aparato semântico em processo de gestação, desenvolvimento e transformação. Por essa razão, as investigações específicas podem retroceder a muito antes do século XVIII e avançar até o presente.

Nesse processo histórico de passagem para a forma de diferenciação funcional, os sistemas parciais emergentes organizam-se, como indica a própria denominação, com vistas a uma função específica (o direito, a arte, a economia, a família, a ciência etc.). Não há, e não pode haver, hierarquia entre eles: cada sistema desenvolve-se de modo próprio, autopoieticamente, 7 observando a partir da sua diferença sistema/ambiente seja a sociedade, sejam os outros sistemas parciais, isto é, observa-os em seu ambiente, deles se diferenciando. "Todo sistema parcial hipostasia o primado de sua própria função" (Corsi, Esposito \& Baraldi, I996: 6I; cf. Luhmann, I997: 748). Todo e cada um, de sorte que essa sociedade diferenciada por funções, a sociedade moderna, seja um sistema policontextural: não somente possibilita, mas exige uma multiplicidade de descrições de sua complexidade; cada sistema parcial oferece a sua, que não invalida a dos outros, mas só serve para si mesmo (pois está assentada na sua diferença sistema/ambiente) ${ }^{8}$

Se assim é, pode-se entender que os distintos sistemas parciais não estão organizados hierarquicamente, que a sociedade não tem centro: não há um sistema global que controla os subsistemas, que são autopoiéticos e fechados operativamente (cf. Luhmann, I997: 42-43, passim). Descrições da sociedade só se podem realizar a partir de um determinado sistema parcial, e portanto não há a ou uma descrição, mas variadas possibilidades. "Sistemas funcionais são, em sua desigualdade, iguais." E, para voltar ao centro do nosso interesse, com a definição e autonomização dos sistemas parciais via diferenciação funcional, as autodescrições dadas pela tradição da diferenciação estratificatória não são mais suficientemente eficazes para possibilitar as comunicações no interior dos sistemas funcionais. Isso exige uma nova semântica. Ela será gestada no interior dos respectivos subsistemas e com vistas às comunicações específicas de cada um deles. ${ }^{9}$ Mas, no mesmo lance, isso significa que em cada um deles será possível acompanhar essas transformações - a obsolescência da semântica gestada na Velha Europa e a gestação de uma nova semântica (cf. Luhmann, I997: 893-958). Luhmann não demonstrou metodicamente essa transformação sistema por sistema; antes deixou-se conduzir por questões estratégicas, por assim dizer, que se apresentaram como resultantes do processo de aumento da complexidade. Tomando exemplos que o leitor pode conferir facilmente em língua portuguesa, temos o problema da ordem social (Luhmann, 20I8: 17-89) - talvez um dos mais evidentes, dada a emergência dessa nova sociedade, a sociedade moderna - ou o problema da propriedade privada (Luhmann, 2019: 19-57), ou o das classes sociais (Luhmann, 2018: 90-138), ou o dos direitos subjetivos (Luhmann, 20I9: I I8-I66), ou o do individualismo (Luh- 
mann, 20I8: I39-2I4), ou o da razão de Estado (Luhmann, 20I9: 58-I I7), ou o da religião tornando-se um sistema parcial "igual em sua diferença” (Luhmann, 2020), e assim por diante.

A moderna teoria dos sistemas costuma nos dizer que observamos sempre a partir de um sistema, ou melhor, que é sempre um sistema que observa, e observa o seu ambiente.

Para que o mundo pudesse ser observado ou, se quisermos, para que "a sociedade" pudesse ser observada seria preciso um sistema cujo ambiente fosse "a sociedade". Qual sistema haveria de ser esse? Certamente não a sociologia, ou qualquer outra disciplina do sistema da ciência. Com efeito, parece que uma tal operação de observação não é possível; parece não haver um sistema que, situado em alguma posição fora do mundo, pudesse observar o mundo como se o mundo fosse o seu ambiente.

Uwe Schimank $(2003)^{\text {Io }}$ reiterou, com perspicácia, o paradoxo característico e decisivo do modo como Luhmann (I997: cap. 5) enfrentou essa questão, ao desenvolver o problema das "autodescrições". Afinal, a sociologia sempre teve pretensões totalizantes, sempre quis falar a partir da sociedade, quando pretendia falar a respeito da sociedade e/ou de algum objeto ou domínio seu. A sociologia fala da política? A partir de algum "todo", identificaria e caracterizaria o sistema da política, indicaria suas operações, seus conceitos, sua evolução e assim por diante. Isso seria mais ou menos o inverso do que a política faria: observaria a sociedade a partir da política - o sistema da política observa a sociedade, situada em seu (do sistema da política) ambiente. Não poderia ser diferente; um sistema pode observar seu ambiente, mas não um "todo" que inclua a si mesmo e o seu ambiente. Pode-se, quando muito, observar observadores observando, ou seja, o sistema da política, nesse exemplo, poderia observar algum outro sistema, digamos, o sistema da economia, observar o seu (do sistema da economia) ambiente, no qual ele, o sistema da política, se encontra. Tal processo pode, em princípio, reproduzir-se infinitamente, em uma espécie de mise en abyme.

Como quer que seja, o "todo" sempre escapa, pois o que quer que se observe, é sempre observado a partir de algum ponto. Ou haveria o ponto de vista de Sirius, que faculta tudo observar? Deslocando-se para fora do mundo?

Muito embora Luhmann tenha publicado uma série de volumes sobre os subsistemas da sociedade - a política da sociedade, a economia da sociedade, a arte da sociedade, a ciência da sociedade (e, paradoxal e provocativamente: a sociedade da sociedade) e assim por diante -, na verdade a observação segue o sentido oposto: o que se vê é a sociedade da política (ou seja, o sistema da política observando a sociedade), a sociedade da economia (o sistema da economia observando), a sociedade da arte e assim sucessivamente...

Não haveria, pois, uma observação do todo, uma observação "da sociedade" (Luhmann, I994: 629; 20I9: I I2). Embora isso pudesse significar a ruína 
da sociologia, que sempre pretendeu se ocupar desse assunto, Luhmann encarou o impasse ou problema como um paradoxo e fundamentou-o na ideia de policontexturalidade, ou seja, de uma sociedade policontextural, nomeadamente, a sociedade moderna. "Autologia refletida" foi o modo como denominou a "descrição sociológica da sociedade na sociedade" (Luhmann, I 997: I I 28-I I42).

Nesse movimento, ele simplesmente radicalizou um conjunto de ideias algo recorrente à sociologia alemã que o precedeu, como aquela ideia de distintas esferas de valor ou ação, possuidoras de legalidades próprias e irredutíveis umas às outras (v. Cohn, I979: I4I-I45; Luhmann, I989: 259ss). O resultado foi assim por ele apresentado:

A reconfiguração em termos de diferenciação funcional consiste na diferenciação de um número maior de sistemas funcionais no interior da sociedade como lei estrutural primária do próprio sistema da sociedade. O acompanhamento de funções específicas é transferido para um subsistema criado para isso, e, de resto, a sociedade é reduzida ao status de ambiente do sistema funcional em questão. Então, a sociedade consiste em si mesma de uma pluralidade de relações sistema/ambiente heterogêneas e perspectivistas. Por exemplo, a partir da economia-e-seu-ambiente; da ciência-e-seu-ambiente; da política-e-seu-ambiente; da educação-e-seu-ambiente; e de nada mais. Ela não conhece nem um vértice comum, nem um centro comum; nem a parte dominante da teoria aristotélica, nem aquele centro da teoria estóica, ao qual todo movimento estava, em última instância, referido. Ela não mais conhece em absoluto uma representação da sociedade na sociedade, e portanto também nenhum lugar 'natural' de sua reflexão. Não é uma sociedade aristocrática, nem pode ser compreendida segundo o modelo de cidade/campo ou centro/periferia. Ela é um sistema de interdependências de relações de sistema/ambiente (Luhmann, 2008b: 204).

Sabemos que os sistemas a que se refere são sistemas autopoiéticos, operacionalmente fechados, autorreferenciados. Como consequência, é preciso compreender a dinâmica própria a cada um deles, que é o que lhes possibilita observar seu ambiente e elaborar descrições desse ambiente - o mais próximo que conseguiremos chegar de uma descrição do todo, se considerarmos que podemos ir acrescentando sucessivamente descrições à medida que vamos passando de um sistema a outro (ou seja, de uma observação a outra). Essa é uma consequência da policontexturalidade.

Eis um ponto que gostaria de destacar: no estoque semântico em operação sincronicamente em diferentes sistemas parciais de uma sociedade policontextural encontramos a possibilidade otimizada de superpor descrições, não obstante o risco que transferências, deslocamentos, contrabandos e aplainamentos de termos, palavras, conceitos, concepções etc. possam trazer e de fato trazem consigo. Palavras carregam sentidos distintos em distintos contextos (no caso, sistemas), não obstante permaneçam indicando e quiçá estabelecendo um rasgo de sentido comum ou potencialmente comum, a partir do qual um vislumbre se descortina - e não mais do que isso. ${ }^{11}$ Ademais, há também friç̧ões desses distintos contextos, que oferecem outros tantos insights dos 
processos em curso, incluindo as mudanças estruturais. Afinal, como indica a última citação, há interdependências na diferenciação funcional, que podem ser exploradas no registro do aparato semântico e de sua transformação. E até mesmo ao revés, pois onde se visa à compreensão também se encontra incompreensão; o processo contingente da produção de sentido é aberto para ambas as possibilidades, como bem o sabemos.

Sugiro, pois, que a produtividade e o esclarecimento sociológico do paradoxo apresentado - não há solução para o paradoxo, há, precisamente, sua produtividade - podem ser encontrados nos estudos de Luhmann acerca da semântica histórica operante nos distintos sistemas parciais. Para evitar equívocos: não se trata de querer anular, superar ou descartar os paradoxos na teoria e nesse caso em particular. Tratar-se-ia, antes, de concretizá-los na dimensão viva e palpável das transformações da estrutura social (para a satisfação dos sociólogos), tornando-os, desse modo, passíveis de apreensão nas transformações semânticas. Digamos, os problemas das interdependências e interconexões entre distintos sistemas parciais - interpenetração e acoplamento estrutural, nos termos de Luhmann (cf. I994: cap. 6; I997: 779-788, 92-I 20, respectivamente) - podem ser pensados na chave de utilização e compartilhamento, ou melhor, difusão, transferência e contrabando - irritações, nos termos de Luhmann (cf. I997: 789-797) - da semântica. Se isso faz sentido, alcançamos o sentido dos estudos (sejam de Luhmann, sejam de outros autores) sobre estrutura social e semântica. (E ainda, como afirma o próprio Luhmann, da atualização do programa de uma sociologia do conhecimento.)

Luhmann (2008e: I42) formulou com tirocínio as consequências do desenho de uma tal teoria: "a unidade da sociedade nada mais é do que essa diferença dos sistemas funcionais". Donde formulo a seguinte questão: a diferença das distintas semânticas (assentadas e/ou operantes em sistemas parciais), em sua covariação com a estrutura social, permitiria vislumbrar a unidade da sociedade? Pois ela certamente permite aquilatar a diferença da sociedade!

Essas questões não passaram despercebidas nem por Luhmann, nem por seus leitores; o que pretendo é antes enfatizar os desenvolvimentos possíveis com vistas aos nexos de estrutura social e semântica, e ao mesmo tempo sugerir a significância desses estudos no interior da teoria e da prática da moderna teoria dos sistemas, em particular, e da sociologia, em geral.

Com a passagem para a diferenciação funcional a sociedade renuncia a ditar um esquema comum de diferença aos sistemas parciais. Enquanto no caso da estratificação cada sistema parcial precisava se determinar mediante uma diferença de hierarquia em face dos outros e somente assim podia obter uma identidade própria, no caso da diferenciação funcional cada sistema funcional determina sua própria identidade - e o faz [...] por meio de uma elaborada semântica da atribuição de sentido, da reflexão, da autonomia. Ademais, a sociedade interessa apenas como ambiente do sistema funcional e não como uma instância superior ou inferior específica. Isso não significa, contudo, que as dependências dos 
sistemas parciais entre si decresçam. Ao contrário, elas crescem. Tomam, contudo, a forma da diferença de sistema e ambiente, não se deixam mais normatizar de modo específico, não se deixam mais legitimar em termos da sociedade como um todo enquanto condição da ordem em geral, porquanto se constituem agora em uma dependência geral e altamente diferenciada das condições do meio ambiente intrassocial em constante mudança (Luhmann, I997: 745).

Transformações semânticas e constituição de estoques semânticos permitem, nessa situação de crescimento, pontuar ou mapear essas condições do meio ambiente, possibilitando ainda que influências do ambiente ("Umwelteinwirkungen", Luhmann, I997: I I8) resultem em irritações, que serão a seguir processadas no interior dos sistemas. Em suma, "A diferenciação funcional afirma que o ponto de vista da unidade, sob o qual uma diferença de sistema e meio ambiente se diferencia, é a função que o sistema que se diferencia (e portanto não o seu ambiente) realiza para o sistema global" (Luhmann, I997: 745746).

Vê-se aqui como Luhmann (cf. I994: 26-27, 593ss., 607; 2008e: 5I, I49) encaminha a questão da diferença de identidade e diferença e, assim, diferencia-se da identidade de identidade e diferença. ${ }^{\text {I2 }}$ Entretanto, interessa novamente menos reconstituir o desenho da teoria e mais apontar os nexos e facilidades que os estudos de estrutura social e semântica podem trazer para a concretização da teoria, ou seja, para o ganho de conhecimento. Não obstante a longueza da citação, prefiro, nesse ponto, ouvir a voz sintética do próprio Luhmann (I994: 620-62I; tb. 624Ss):

Faz parte das peculiaridades da semântica na nova Europa que se desenvolva uma reflexão do sistema [...] e assuma a forma de teoria. Pode-se falar em teorias de reflexão quando a identidade do sistema, em distinção ao seu ambiente, não é somente designada (de modo que se saiba aquilo que é visado), mas sim trabalhada conceitualmente de tal modo, que comparações e relacionamentos podem ser estabelecidos. Desse modo, originaram-se, desde o século XVII, teorias do Estado orientadas para o problema de que o poder político mais elevado precisa ser superior a todas as forças em um território e precisa poder decidir todo e qualquer conflito e, apesar disso, precisa ser impedido de um uso arbitrário. O resultado é uma teoria do moderno Estado constitucional, cujos aspectos parciais, por exemplo a divisão de poderes, a representação democrática, a proteção dos direitos fundamentais, são funcionalizados com respeito a esse problema. Para o sistema da ciência originam-se teorias do conhecimento e posteriormente teorias da ciência que pretendem esclarecer como a identidade na diferença de conhecimento e objeto é possível - seja como autocondicionamento da consciência transcendental, seja na forma de um processo dialético, seja na forma de uma pragmática aberta a prova. Também para o sistema educacional colocam-se, desde a segunda metade do século XVIII, problemas de reflexão próprios ao sistema, que tratam, por exemplo, como finalidades da educação, a diferença de buscar a perfeição e buscar algo que seja útil ou o problema de como se poderia alcançar a liberdade. Para o sistema do direito coloca-se sobretudo a questão de como, após o abandono do direito natural, se poderia fundamentar como necessária a validade sempre contingente do direito positivo. Por volta de I800 fala-se, 
exatamente com relação a isso, em filosofia do direito positivo (Feuerbach); hoje, em 'teoria do direito'. No sistema da economia, desde os fisiocratas e desde Adam Smith, as teorias de reflexão específicas do sistema (derivadas das análises da troca, da produção e/ou da distribuição) se desvinculam da antiga literatura de aconselhamento dos príncipes. Mesmo no domínio das relações íntimas somente no século XVIII começam a se desenvolver, sobre a base de ideias anteriores de amour passion, concepções para a unidade sistêmica de amor e casamento; as limitações externas recuam e já se está apto a aceitar que o amor prepara ele mesmo toda a felicidade e desgraça que se experimenta.

O que vemos nessa citação é um elencar de sistemas sociais parciais - da política, da ciência, da educação, do direito, da economia e das relações íntimas - que se constituem como sistemas autorreferidos, autopoiéticos e fechados operacionalmente e, nesse processo histórico, desenvolvem internamente mecanismos - códigos, programas, semânticas ${ }^{13}$ - que lhes permitem operar, vale dizer, lidar com a complexidade com vistas a reduzi-la, realizando para isso diferenciações. Ao mesmo tempo, o desenvolvimento dos sistemas propicia um incremento de complexidade, na forma das relações que se establecem entre seus elementos, de sorte que temos um movimento duplo de incremento e redução. Tais sistemas, em se fechando, negam qualquer hierarquia ou centralidade a si e a qualquer outro sistema; o todo nada mais é do que a existência sincrônica e dinâmica de distintos sistemas autônomos. "Sistemas funcionais são, em sua desigualdade, iguais." Tudo isso também resulta em aumento de complexidade, vale dizer, um aumento nas possibilidades e modalidades das operações em geral, no interior de cada um dos sistemas, o que por sua vez significa: no ambiente dos outros sistemas. ${ }^{14}$

Notemos que Luhmann indicou como característica decisiva o fato de que esses sistemas ganham uma dimensão de reflexão que possibilita comparações e aproximações. Pode-se, portanto, comparar os distintos sistemas e observar como cada um deles desenvolve um código próprio, que lastreia suas operações, e como cada um deles desenvolve (ou, caso se prefira, lança mão de) uma semântica própria, adequada justamente a essa reflexão que ele produz internamente e para si mesmo - porque ele sempre pode parar de produzir e processar sentido, e com isso perecer. Como ensina o coelho de Alice, é preciso correr sem parar para ficar no mesmo lugar.

Que em todos esses sistemas seja possível detectar esse processo de reflexão do próprio sistema, indica a cesura epocal que a teoria dos sistemas luhmanniana assume e defende: a passagem da Velha para a Nova Europa, da diferenciação estratificatória para a diferenciação funcional. A análise em paralelo dos distintos sistemas na situação de mudança oferece uma visada privilegiada para o sociólogo e consuma uma forma de sociologia histórica guarnecida teoricamente. Permite, ainda, elaborar o problema das sincronias e das diferentes temporalidades características dos distintos sistemas, indicando uma vez mais o grau de complexidade assumido pela sociedade moderna. Com a 
transição da diferenciação estratificatória para a funcional as antigas hierarquias, que possibilitaram primazias quer à política, quer à religião, deixam de existir, substituídas pela igualdade de todos os desiguais sistemas: cada um por si e nenhum por todos.

Os apontamentos precedentes sugerem um esforço de Luhmann em conjugar de modo consistente teoria e história. Com efeito, até onde vejo, nenhum outro sociólogo esquadrinhou a emergência do mundo moderno em tão variados domínios, ${ }^{15}$ embora Luhmann o faça, evidentemente, sob o prisma de seus próprios desenvolvimentos no âmbito da teoria dos sistemas sociais, e procurando oferecer uma espécie sui generis de atualização do programa de uma sociologia do conhecimento. A amplitude dos temas e problemas abordados, sempre modulados com vistas ao processo de emergência do mundo moderno - a passagem da Velha Europa para a sociedade mundial -, a passagem do primado da diferenciação estratificatória para o primado da diferenciação funcional, não encontra par na sociologia, dado que empreitadas gigantescas como a de Michael Mann (publicada de I983 a 20I3) ou de Immanuel Wallerstein (publicada de I974 a 20II) trabalham com recortes temporais distintos.

Trata-se de um momento-chave tanto para o modelo teórico luhmanniano como para a compreensão do mundo em que vivemos. Esse é, aliás, um ponto relevante na constituição da sociologia histórica luhmanniana. Usualmente, não se considera a contribuição de Luhmann para uma sociologia his tórica; antes, o contrário: seus textos são tomados como elaborações teóricas, não raro extremamente abstratas e enviesadas por uma terminologia obscura e idiossincrática, técnica e, ainda mais, emprestada de outros domínios de conhecimento. ${ }^{16}$ Mas isso é um erro. Em seu esforço de desenvolvimento da teoria da sociedade, Luhmann preocupou-se ininterruptamente com o nexo de sociologia e história e procurou sempre guarnecer seus desenvolvimentos e propostas teóricas com estudos históricos que atestassem a viabilidade e os ganhos cognitivos do modelo que propunha. Em contrapartida, a teoria oferece uma embocadura para o tratamento do "histórico", sua circunscrição, análise, exposição, significação.

De certo modo aproximando-se dos desenvolvimentos da história dos conceitos (e em especial a partir da perspectiva de Koselleck, como já foi lembrado), as ideias de "semântica" e de "semântica elaborada/culta" desempenham papel decisivo no enraizamento histórico dos processos de mudança social. A semântica investigada lastreia as comunicações, operações básicas dos sistemas sociais, e sua mudança permite acompanhar a covariação com a estrutura social.

Não livre de divergências e controvérsias significativas, não raro marcada por nacionalismos metodológicos, a especialidade "sociologia histórica" encontra, hoje, variados modos de concretização. ${ }^{17}$ Interessa apenas assinalar que Luhmann tem em vista uma teoria da sociedade que não renuncia a modelos de mudança social de larga escala; mas, ao mesmo tempo, são estudos deta- 
lhados da mudança histórica que possibilitam e dão lastro e sentido ao modelo teórico. Donde sucede que a preocupação com a relação de teoria e história resulta em uma solução específica ou modalidade de sociologia histórica. Se tomarmos uma circunscrição e definição como a oferecida pelo mais completo léxico enciclopédico da sociologia contemporânea atualmente disponível, podemos situar sem mais os estudos de Luhmann no âmbito da sociologia histórica contemporânea:

A 'sociologia histórica' é o exame sistemático do passado com vistas a informar e a reconstruir os achados empíricos e as teorias acerca do mundo. [...] Hoje ela é caracterizada pelo pluralismo metodológico, assim como por um profundo engajamento com as questões sociocientíficas da mudança social de larga escala e a institucionalização das sociedades modernas, e os fundamentos epistemológicos da história das ciências sociais (Wilson \& Adams, 2015: 27).

Como se evidencia, os esforços luhmannianos com respeito à covariação de estrutura social e semântica recobrem com perfeição essa definição de sociólogos norte-americanos, que no entanto permanecem desconhecendo a contribuição do sociólogo alemão. Para uma reconstrução da empresa luhmanniana, sua afiliação a um rótulo é de pouca importância, obviamente. Não obstante, isso também permite compreender melhor o alcance de suas contribuições, ainda mais porque, como alguém já disse, "a sociologia de Luhmann, no final das contas, ainda não foi recebida na sociologia" (Jahraus et al., 201 2: 400). Como quer que seja, cabe aos leitores a tarefa de compor e recompor mentalmente o conjunto dos estudos acerca da correlação de estrutura social e semântica, de modo a montar o quebra-cabeça e então, com a ampla paisagem à vista, avaliar o rendimento da empreitada.

Se quisermos indicar um exemplo do trabalho concreto de Luhmann na direção dos estudos sobre estrutura social e semântica, seu livro sobre o amor como paixão ocupa uma posição privilegiada, por ser o mais desenvolvido deles. Com efeito, o que era de início mais um estudo a ser inserido na série de livros sobre estrutura social e semântica acabou por desenvolver-se e tornar-se um volume autônomo. ${ }^{18} \mathrm{Em} O$ amor como paixão, Luhmann procura conjugar a investigação semântica com a teoria dos meios de comunicação simbolicamente generalizados; de certo modo, esse pequeno grande livro sintetiza aspectos centrais de toda a teoria luhmanniana, como se pode aferir neste passo:

O aumento da probabilidade do improvável - eis a fórmula que enlaça a teoria da sociedade, a teoria da evolução e a teoria dos meios de comunicação. A normalização de estruturas sociais improváveis coloca altas exigências aos meios de comunicação, ela se reflete em sua semântica, e evolução é a ideia que deve explicar como algo assim vem a ocorrer (Luhmann, I995b: IO; v. tb. I997: 4I3).

O trecho revela-nos um escopo que, bem observado, ultrapassa em muito a presente discussão; mas indica onde se a deve situar. Para mim, interessa reter a ideia de que a semântica atua em conjunto com os meios de comunica- 
ção simbolicamente generalizados, e evolução indica a passagem para a sociedade moderna, funcionalmente diferenciada. No caso em questão, o sistema parcial desenvolve sua semântica em tal grau, que um dos elementos assume a função de meio de comunicação simbolicamente generealizado: o amor como paixão no âmbito do sistema parcial das relações íntimas; caso se queira, da intimidade.

No termos formulados ao início, estamos falando de uma semântica que lastreia e possibilida o sentido generalizado no mais alto grau ("tipificação", como se viu; "normalização", como se formula no passo); o que concorre para aumentar a probabilidade da comunicação improvável. Essa comunicação estabiliza as operações do sistema, possibilitando a sua reprodução, ou seja, que ele continue a existir no momento seguinte e repita a seguir as operações, e assim sucessivamente, existindo ao longo do tempo ou, caso não consiga repetir as operações e garantir um mínimo de ordem nas operações internas e, assim, sua separação de seu ambiente, pereça. Pois sistemas sociais são extremamente dinâmicos, e nada garante que o sucesso de uma operação afiance o sucesso da próxima operação - como bem o sabemos: casamentos ruínam, a paixão esmorece, o amor acaba e assim por diante. Estamos falando de operações que garantem provisoriamente o "aumento da probabilidade do improvável”, mas isso não garante que o improvável ocorra. Era possível, mas improvável, que, em uma quadrilha bem conhecida, Teresa amasse João, mas a história tomou outros rumos, e Teresa foi parar no convento, enquanto João foi para os Estados Unidos - para não falar do que ocorreu com Maria, Joaquim e Lili. O poema elabora a improbabilidade de que o amado ame o amante em uma situação em que, em termos de análise, Alter e Ego se alternam continuadamente, ou seja, de que o amante ame o amado.

Não obstante todas as dificuldades e improbabilidades, pessoas acabam amando, e isso somente ocorre - amados amando amantes e amantes amando amados - porque há uma semântica desenvolvida no sistema social das relações íntimas que é posta a funcionar e produzir sentido: reduz o improvável, por vezes a tal ponto, que ele ocorre (o que, infelizmente, não ocorreu com João e Teresa, ao menos a crermos no que o poeta nos diz).

Em seu livro, Luhmann historiou e demonstrou o processo de uma semântica do amor conectado à diferenciação de um sistema de relações íntimas. No âmbito da sociedade estamental, da diferenciação estratificatória, situações de nascimento e status definiam o universo e a dinâmica das comunicações íntimas - e não somente do amor, mas também e sobretudo da amizade, assim como da família. Com sua progressiva ruína, a emergência de um sistema social de relações íntimas possibilitou formas de relações sociais nas quais fosse possível combinar a enorme massa de relações impessoais (que usualmente se usa para caracterizar a sociedade moderna, a sociedade de "massas", do "homem na multidão" etc.) com relações pessoais altamente intensivas, nas quais o que 
há de mais pessoal, individual e único (o que usualmente se pensa sob a rubrica do "individualismo qualitativo") é comunicado e confirmado precisamente nas relações amorosas. Pois é para o amante que o amado como um todo aparece em sua individualidade esplendorosa e plena, e vice-versa (cf. Waizbort, 20I8; 2008). A constituição do sistema de relações íntimas, vê-se, possibilita reduzir complexidade: oferece solução a um problema estrutural e decisivo da sociedade moderna, o conflito dos individualismos qualitativo e quantitativo, para lembrarmos uma formulação sociológica célebre (cf. Simmel, 2013). "Em comparação com formações sociais mais antigas, a sociedade moderna caracteriza-se por uma intensificação em duplo sentido: em virtude de mais possibilidades de relações impessoais e em virtude de relações pessoais mais intensivas" (Luhmann, I995b: I3). Luhmann lembra, seguindo Simmel, que não se trata de ampliar o raio de extensão das relações pessoais - seria uma sobrecarga para o indivíduo manter uma ampla malha de relações muito intensas, e justamente para isso a impessoalidade é funcional e reduz complexidade -, mas sim de intensificar ao máximo umas poucas relações, de que a relação amorosa é o caso extremo. Amantes amam intensamente; descendo alguns degraus de intensidade, somos amigos; e amizades comportam um gradiente amplo de intensidades, até se esgarçar nas distâncias temporais e espaciais, ou perder-se nos rincões do tempo que se foi e se perdeu. Ao passarmos para o âmbito das relações impessoais, os papeis sociais nos permitem resolver as dificuldades com que nos defrontamos, sem que com isso precisemos investir grandes energias, embora sempre também o possamos fazer (por exemplo, para comprarmos algo, como compradores anônimos que se defrontam com vendedores também anônimos). Na relação amorosa, ao contrário, o que é individual, único, específico do amado é justamente o que o faz ser amado pelo amante. A ideia moderna de individualidade, até onde pode fazer sentido, depende dessa semântica do sistema das relações íntimas, porque é ela que a concretiza do modo o mais acabado; investigando essa semântica, Luhmann (I995b: I5, I35, 208; 2008a; 2017a: 90-94; I997: I0I6ss; 2017b: 503; 2018) forneceu elementos para uma "sociogênese da individualidade". Aqueles interessados em inventariar e explorar essa nova semântica podem iniciar-se com alguns "fragmentos de um discurso amoroso" (Barthes, I977). Ali estão compiladas materializações dessa semântica ("tipificação", "normalização"), mobilizada sempre novamente pelos amantes e reproduzida e ensinada sem cessar pelos livros, pelas revistas, pelos filmes e pela TV, e agora também por meios eletrônicos todos eles meios de difusão (cf. Luhmann, I997: 202ss, 3I 2ss.).

No caso em tela, Luhmann visava ao sistema emergente das relações íntimas - pelas razões apontadas: aumento da complexidade e necessidade de redução de complexidade; sua emergência exigia a elaboração de uma semântica nova e própria. 
A exaltação do amor como paixão, que administra soberanamente o seu próprio império, aflorou somente no século XVII e de início para relações extramaritais. Ainda no século XVIII o matrimônio sem o consentimento dos pais era muito pouco provável (o que não impedia que um jovem atraente seduzisse uma rica herdeira e encontrasse um sacerdote que os casasse). Só no curso do século XVIII ocorreu na Europa a ideia mundialmente extraordinária de que apenas o amor deveria decidir sobre o casamento, e isso segundo o modelo dos romances e com a inclusão da nobreza. Somente agora o princípio do enlace matrimonial, ao menos idealmente, neutralizou a intervenção da estratificação social.

Análises desse tipo podem ser conduzidas também para outros sistemas funcionais. Por toda parte encontramos a reconfiguração com vistas à dinâmica própria e a dissolução das premissas que estavam garantidas pela estratificação (Luhmann, I997: 73I).

Ao discutir o amor como meio de comunicação simbolicamente generalizado (Luhmann, I995b; I986: 6-7; I997: 344-348; 2017b: 499-505), Luhmann o aproxima de outros meios, tais como a verdade, o dinheiro, o poder, também eles objeto de processos de diferenciação funcional e correlatas constituições de semânticas próprias naquele momento de cesura epocal.

Voltando: se não há mais a estrutura estamental capaz de resolver como amar e com quem casar, como se definem os emparelhamentos dos casais (a quadrilha do poema), como essa questão pode encontrar solução? A liberdade que essa mudança social propiciou trouxe consigo um problema, que exige resposta. E ela é elaborada na definição de um código, que instrui quem amar e como amar. "O meio [de comunicação] amor não é um sentimento, mas sim um código de comunicação, segundo cujas regras se exprimem, formam, simulam, supõem, negam sentimentos, e se pode haver com as consequências disso tudo quando a comunicação correspondente se realiza" (Luhmann, I995b: 23). Em meio a uma sociedade de milhões de pessoas, qual é a alma gêmea? A isso responde o código do amor. Ele afirma: a alma gêmea é aquela que você ama. E, para mostrar o que é o amor, o código desenvolve uma consistente e elaborada carga semântica: a paixão, o excesso, o ideal, a sexualidade, a individualidade, o romantismo etc. (novamente: “tipificação", "normalização"). Uma semântica em processo, que vai se alterando ao longo do tempo, mas que funciona como redutora de complexidade, "intensificando a probabilidade do improvável". O processo amoroso permite que Ego e Alter se afirmem como Ego e Alter, que cada um se perceba simultaneamente como amante e amado: uma dimensão de reflexividade constituinte do amor moderno e correlacionada com a noção moderna de indivíduo, que é autorreflexiva - "o amor orienta-se para o outro como se orienta para uma relação com o mundo de caráter próprio, para um indivíduo singularizado e, assim, para um mundo visto de um modo singularizado" (Luhmann, I995b: I35; cf. Waizbort, 2008; 2018). .9 Pode-se também desenvolver o argumento em sentido oposto, ou seja, procurar mostrar como 
só com uma semântica disponível e eficaz se torna possível que o sistema se diferencie - do contrário, como poderia ele garantir a reprodução de suas operações, vale dizer, sua existência?

Estruturas semânticas desempenham papel decisivo na dinâmica intrínseca e contínua dos sistemas sociais autorreferenciados e autopoiéticos. Elas garantem a realização ou não das operações do sistema, ou seja, sua continuidade no tempo ou ruína. Pois suas operações dependem de comunicações, comunicações dependem de sentido (ou não se concretizam), e semântica guarnece e sustenta a produção de sentido. Semântica social, portanto, está ligada à memória social - "algo como a memória oficial da sociedade" (Luhmann, I997: 627) -, ao lembrar e esquecer, pois garante, lembrando, a reprodução-repetição das operações, a atualização de sentido; esquecimento significa que sentido não é atualizado, e o sistema não se reproduz ou mantém (cf. Martens, 2003).

As ocorrências anteriores dos termos "covariação" e "interdependências", assim como a referência a "condições evolutivas circulares", apontam para uma questão decisiva desta argumentação e do problema do nexo de estrutura social e semântica que, seguindo certo uso luhmanniano, foi indicado sob a rubrica da "covariação". Trata-se do problema da emergência.

Refiro-me à questão, amplamente discutida na teoria dos sistemas, mas não só nela, de como propriedades antes não existentes passam a existir a partir dos nexos que se estabelecem entre elementos, no âmbito da auto-organização e, no nosso caso, do fechamento operacional e da autopoiesis dos sistemas sociais.

Destarte, a complexidade dos sistemas sociais possibilita e pede, em vista da necessidade de redução de complexidade, a emergência de estruturas, padrões, roteiros, programas, propriedades e operações.

À medida que um sistema se torna mais complexo, novas e inesperadas propriedades são produzidas. Formulando do modo mais simples, ocorre que sistemas sociais engendram uma complexidade estrutural que lhes é própria e que se constitui como constituição mesma do sistema em sua diferença frente ao ambiente (Luhmann, I997: I34-I35, 4I3, 455, 9I 8 com indicação bibliográfica a respeito da emergência). Procurei concentrar a abordagem a partir do problema das formas de diferenciação social, que estão conectadas a uma teoria da evolução, posto que a complexidade própria de um sistema social é engendrada por ele mesmo e nada mais; essa dinâmica é a evolução desse sistema. Ele se torna mais complexo porque, de algum modo, abriga diversidade e diferença. Correlata, paralela a essa evolução dos sistemas, é a evolução das semânticas (parallelgeführte Semantik é a expressão utilizada por Luhmann, I997: 744). Esse é o nó da covariação, que também pode ser formulada como coevolução (lembremo-nos da menção anterior à "evolução de ideias") (Luhmann, I997: 536-556). Variam em paralelo, evoluem em paralelo: os sistemas e as semânticas. Essas considerações nos permitem, para finalizar, destacar a posição ímpar dos estu- 
dos acerca de semântica e estrutura social no interior da moderna teoria dos sistemas sociais. Sistema e estrutura são dois pilares da concepção de sociedade. ${ }^{20}$ Como se viu, comunicações são as operações basilares dos sistemas sociais, donde sua dinâmica e transformação constantes. O encadeamento de comunicações é o processo de produção e reprodução ininterrupta do sistema, que, do contrário, perece. Portanto, sistema é dinâmica e transformação ininterruptas. Por outro lado, estrutura garante estabilidade por meio de padrões repetitivos ou fixados - por meio de tipificação e normalização, como também se salientou. Duração e transformação, estrutura e sistema complementam-se. Semântica social concretiza-se nessas duas dimensões, garantindo a dinâmica das comunicações e a produção de sentido, e ao mesmo tempo estruturas duráveis - mas evidentemente também sujeitas a transformações ao longo do tempo, dado que a complexidade do sistema da sociedade e a contingência de suas operações exigem que a semântica se transforme (cf. Luhmann, I980b: I5). Em conexão com a diferenciação social, estática e dinâmica encontram-se no domínios da semântica e lastreiam o realizar do sistema da sociedade. É por essa razão que estamos também nos domínios de uma teoria da evolução (Luhmann, I997: 4I4).

Enfim, para retornarmos à quadrilha com que nos deparamos, podemos agora dizer que a mobilização da semântica gestada no âmbito da transformação epocal da passagem para a diferenciação funcional poderia ter possibilitado - embora não garantido, e não sabemos o que de fato ocorreu - que Teresa e João tivessem casado: mas teria sido preciso que eles de algum modo se declarassem, mobilizando para isso uma quantidade infindável de fórmulas do amor, explorando passo a passo suas possibilidades, testando sem cessar seus limites, emergindo no brilho único e fulgurante do amor (cf. Waizbort, 2018). Nem sempre ocorre; talvez raramente ocorra; mas pode ocorrer. Possibilitar que ocorra diz respeito à fórmula "tornar mais provável o improvável" (cf. Luhmann, I997: 4I6, 573, passim). O mesmo vale, como já se disse, para os outros sistemas parciais. Cada um deles e todos eles desenvolvem suas semânticas próprias, que lhes possibilitam, e somente a eles, produzir e reproduzir sentido - do contrário, perecem. Ao final, vale o mote: cada um por si e nenhum por todos.

Recebido em 9/8/20I9 | Revisto em 30/I/2020 | Aprovado em I/5/2020

Leopoldo Waizbort é professor de sociologia na USP e pesquisador do CNPq. Autor de As aventuras de Georg Simmel (2000) e A passagem do três ao um: crítica literária - sociologia - filologia (2007). 


\section{NOTAS}

I Este texto, inédito, incorpora e reelabora trechos de introduções escritas para os volumes I, 2 e 3 dos livros de Luhmann, Teoria dos sistemas na prática, publicados pela editora Vozes em 2018, 2019 e 2020.

2 O próprio Luhmann (I994: I4) utiliza a imagem do labirinto na caracterização de sua teoria.

3 Foram publicados quatro volumes com o título Gesellschaftsstruktur und Semantik. Studien zur Wissenssoziologie der modernen Gesellschaft [Estrutura social e semântica. Estudos para a sociologia do conhecimento da sociedade moderna] em I980, I98I, I989 e I995; o volume Liebe als Passion. Zur Codierung von Intimität [O amor como paixão. Sobre a codificação da intimidade], em I982; e Ideenevolution [Evolução das ideias], póstumo, em 2008.

4 "Uma teoria da evolução social renuncia a explicações causais [...]. Ela substitui o esquema causal pela aceitação de condições evolutivas circulares" (Luhmann, I997: 572, itálicos meus, tb. 4I5; v. ainda Luhmann, I980b: 7-9; trad. Luhmann, 20I8: I3-I4). Nessa citação e em todas as demais em idiomas estrangeiros a tradução é de minha responsabilidade.

5 Luhmann aproxima-se da concepção de semântica desenvolvida por Reinhart Koselleck em variados estudos e na elaboração do dicionário enciclopédico Geschichtliche Grundbegriffe (cf. Luhmann, I980a: I9-2I; I986: 2; Jahraus et al., 20I2: 215; Mueller \& Schmieder, 2016: 337ss).

6 Um resumo mais extenso oferecem Corsi, Esposito \& Baraldi, I996: 58-63.

7 Já se observou a relação de semântica e autopoiesis. Sobre a autopoiesis, ver Luhmann, I994, passim; I997, passim; Corsi, Esposito \& Baraldi, I996: 31-34; Jahraus et al., 2012: 69-7I.

8 "A sociedade moderna é um sistema policêntrico, policontextural. Ela emprega códigos muito variados, 'frames' muito diversos, distinções condutoras totalmente diversificadas conforme o caso, se ela descreve o mundo e a si mesma do ponto de vista de uma religião ou do ponto de vista do direito ou do ponto de vista da política, do ponto 
de vista da educação ou do ponto de vista da ciência." (Luhmann, I996a: 44). Sobre a policontexturalidade, que Luhmann toma da lógica de G. Günther, ver Luhmann, I997: 36, 88, I094, II32, II4I; Jahraus et al., 2012: 280-283.

9 Para o que os meios de comunicação simbolicamente generalizados, gestados no âmbito de cada sistema parcial, desempenharão um papel significativo (v. Luhmann, I997: 3I6ss).

Io Que acompanho nas considerações subsequentes.

I I Em sentido similar, v. Stichweh, 2006: 6.

I 2 A bem da verdade, Luhmann não estava preocupado com a unidade da sociedade, pois problemas de unidade remetem a uma lógica distinta daquela que modula sua teoria; estava preocupado com a diferença de identidade e diferença, e não com a unidade-identidade de identidade e diferença (cf. Jahraus et al., 20I2: 264).

I3 Sobre códigos e programas, que não posso abordar neste artigo, v. Jahraus et al., 2012: 7I-73; Corsi, Esposito \& Baraldi., I996: 40-43, I3I-I33.

I4 Embora o que ocorra no ambiente de um sistema seja, para esse sistema, sem forma: "O ambiente é o fundamento/fundo do sistema, e o fundamento/fundo é sempre algo sem forma" (Luhmann, I994: 602).

I5 Luhmann escreveu numerosos estudos sobre a correlação de estrutura social e semântica, que ademais aparece recorrentemente, embora menos desenvolvida, ao longo de toda a sua obra escrita. (Cf. Waizbort, 2020)

I6 O próprio Luhmann (I996b: I3) reconhece, com concisão e clareza, as dificuldades: "Por una parte se deben al nivel de abstración de los conceptos, por otra a la interdisciplinariedad de los recursos" (v. tb. Luhmann, 2002; Corsi, Esposito \& Baraldi, I996: I5-I8; Jahraus et al., 20I2: IX-XI, 399-407).

I7 A título de exemplo, vejam-se as formulações bastante variadas a respeito, não raro expondo nacionalismos metodológicos em ação: Tilly, 200I; Osterhammel, 2006; Steinmetz, 2007; Sewell Jr., 2005 (há uma edição brasileira: Lógicas da história. Petrópolis: Vozes, 2017); Dofour, 2015; Paci, 20r3. Nelas, Luhmann não é objeto de consideração. 
I8 Cf. Luhmann, I98I: 7. Como, por outro lado, trata-se de um assunto que Luhmann já havia desenvolvido em curso, torna-se possível aquilatar o deslocamento operado com vistas a contemplar o problema da covariação de estrutura social e semântica, dado que na versão inicial da problematização esse não era o foco. O tratamento anterior do problema ocorreu no início da atuação de Luhmann em Bielefeld, em um seminário de I969 já intitulado "Liebe als Passion" (v. Luhmann, 2008d).

I9 No processo descrito e analisado em Liebe als Passion, vemos passo a passo o desenrolar semântico, dos finais da Idade Média ao presente: um amor racional, um amor galante, um amor romântico, um amor burguês, um amor problemático, a que corresponde um código que vai da idealização, passando pelo paradoxo, ao problema (cf. Luhmann, 1995b: 197, 213; Barthes, 1977).

20 Baseio-me e acompanho Jahraus et al., 2012: II5.

\section{REFERÊNCIAS BIBLIOGRÁFICAS}

Barthes, Roland. (I977). Fragmentos de um discurso amoroso. I4 ed. Rio de Janeiro: Francisco Alves.

Cohn, Gabriel. (1979). Crítica e resignação. São Paulo: T.A. Queiroz.

Corsi, Giancarlo; Esposito, Elena \& Baraldi, Claudio. (I996). GLU. Glosario sobre la teoría social de Niklas Luhmann. Ciudad de México: Universidad Iberoamericana.

Dofour, Frédérick Guillaume. (20I5). La sociologie historique. Québec: Presses de l'Université du Québec.

Jahraus, Oliver et al. (orgs.). (2012). Luhmann Handbuch. Stuttgart/Weimar: J.B. Metzler.

Luhmann, Niklas. (2020). Teoria dos sistemas na prática, v. 3. Petrópolis: Vozes.

Luhmann, Niklas. (20I9). Teoria dos sistemas na prática, v. 2. Petrópolis: Vozes.

Luhmann, Niklas. (2018). Teoria dos sistemas na prática, v. I. Petrópolis: Vozes.

Luhmann, Niklas. (2017a) [1995]. Die Realitaet der Massenmedien. 5 ed. Wiesbaden: VS. 
Luhmann, Niklas. (20I7b). Systemtheorie der Gesellschaft. Berlin: Suhrkamp.

Luhmann, Niklas. (2009) [1975]. Soziologische Aufklaerung, v. 2.6 ed. Wiesbaden: VS.

Luhmann, Niklas. (2008a) [1987]. Die gesellschaftliche Differenzierung und das Individuum. In: Soziologische Aufklaerung, v. 6.3 ed. Wiesbaden: VS, p. I20-I36.

Luhmann, Niklas. (2008b). Ideenevolution. Frankfurt am Main: Suhrkamp.

Luhmann, Niklas. (2008c) [I98I]. Ideengeschichte in soziologischer Perspektive. In: Luhmann, Niklas. Ideenevolution. Frankfurt am Main: Suhrkamp, p. 234-252.

Luhmann, Niklas. (2008d) [1969]. Liebe. Frankfurt am Main: Suhrkamp.

Luhmann, Niklas. (2008e) [I986]. Ökologische Kommunikation. 5 ed. Wiesbaden: VS.

Luhmann, Niklas. (2002) [1979]. Ciência incompreensível. Problemas de uma linguagem própria à teoria. Novos Estudos, 63, p. 5I-59.

Luhmann, Niklas. (I999) [I982]. A sociedade mundial como sistema social. Lua Nova, 47, p. 186-200.

Luhmann, Niklas. (1997). Die Gesellschaft der Gesellschaft. Frankfurt am Main: Suhrkamp.

Luhmann, Niklas. (1996a). Die neuzeitlichen Wissenschaften und die Phänomenologie. Wien: Picus.

Luhmann, Niklas. (I996b) [1989]. Prefácio. In: Corsi, Giancarlo; Esposito, Elena \& Baraldi, Claudio. GLU. Glosario sobre la teoría social de Niklas Luhmann. Ciudad de México: Universidad Iberoamericana, p. II-I3.

Luhmann, Niklas. (1995a). Gesellschaftsstruktur und Semantik. Studien zur Wissenssoziologie der modernen Gesellschaft, v. 4, Frankfurt am Main: Suhrkamp.

Luhmann, Niklas. (1995b) [1982]. Liebe als Passion. Zur Codierung von Intimität. 2 ed. Frankfurt am Main: Suhrkamp. Luhmann, Niklas. (1994) [1984]. Soziale Systeme. 5 ed. Frankfurt am Main: Suhrkamp.

Luhmann, Niklas. (1992) [I990]. Die Wissenschaft der Gesellschaft. Frankfurt am Main: Suhrkamp. 
Luhmann, Niklas. (1989). Gesellschaftsstruktur und Semantik. Studien zur Wissenssoziologie der modernen Gesellschaft, v. 3. Frankfurt am Main: Suhrkamp.

Luhmann, Niklas. (I986). Preface to the English Edition. In: Luhmann, Niklas. Love as passion. Cambridge: Harvard UP.

Luhmann, Niklas. (198I). Gesellschaftsstruktur und Semantik. Studien zur Wissenssoziologie der modernen Gesellschaft, v. 2. Frankfurt am Main: Suhrkamp.

Luhmann, Niklas. (I980a). Gesellschaftliche Struktur und Semantische Tradition. In: Gesellschaftsstruktur und Semantik. Studien zur Wissenssoziologie der modernen Gesellschaft, v. I. Frankfurt am Main: Suhrkamp, p. 9-7I.

Luhmann, Niklas. (1980b). Gesellschaftsstruktur und Semantik. Studien zur Wissenssoziologie der modernen Gesellschaft, v. I, Frankfurt am Main: Suhrkamp.

Mann, Michael. (I986-2013). The sources of social power. Cambridge: Cambridge UP.

Martens, Wil. (2003). Struktur, Semantik und Gedächtnis. Vorbemerkungen zur Evolutionstheorie. In: Schimank, Uwe \& Giegel, Hans-Joachim (orgs.). Beobachter der Moderne. Frankfurt am Main: Suhrkamp, p. 167-203.

Mueller, Ernst \& Schmieder, Falko. (2016). Begriffsgeschichte und historische Semantik. Berlin: Suhrkamp.

Osterhammel, Jürgen. (2006). Gesellschaftsgeschichte und Historische Soziologie. Geschichte und Gesellschaft, 22 (Sonderheft), p. 8I-IO2.

Paci, Massimo. (2013). Lezioni di sociologia storica. Bologna: Il Mulino.

Schimank, Uwe. (2003). Theorie der modernen Gesellschaft nach Luhmann - eine Bilanz in Stichworten. In: Schimank, Uwe \& Giegel, Hans-Joachim (orgs.). Beobachter der Moderne. Frankfurt am Main: Suhrkamp, p. 26I-298.

Sewell Jr., William H. (2005). Logics of History. Chicago: Chicago UP (Chicago Studies in Practices of Meaning).

Simmel, Georg. (2013) [1903]. As grandes cidades e a vida do espírito. In: Botelho, André (org.). Sociologia. São Paulo: Cia. das Letras, p. 3II-329. 
Steinmetz, George. (2007). The historical sociology of historical sociology. Germany and the United States in the Twentieth Century. Sociologica, 3, p. I-28.

Stichweh, Rudolf. (2006). Semantik und Sozialstruktur. Zur Logik einer systemtheoretischen Unterscheidung. In: Tänzler, Dirk; Knochblauch, Hubert \& Soeffner, Hans Georg (orgs.). Neuen Perspektiven der Wissenssoziologie. Konstanz: UKV, p. I57-I7I (citado segundo versão digital, p. I-8).

Tilly, Charles. (200I). Verbete "Historical Sociology". In: Smelser, Neil J. \& Baltes, Paul B. (eds.). International Encyclopedia of the Behavioral and Social Sciences, v. Io. Amsterdam: Elsevier, p. 6753-6757.

Waizbort, Leopoldo. (2020). Apresentação. In: Luhmann, Niklas. Teoria dos sistemas na prática, v. 3. Petrópolis: Vozes. Waizbort, Leopoldo. (2018). Cheek to cheek: Ginger e Fred vão ao paraíso. ARS, 16/32, p. 197-205.

Waizbort, Leopoldo. (2008). O beijo dos amantes. In: Bueno, Maria Lúcia \& Camargo, Luiz Octávio de Lima (orgs.). Cultura e consumo. Estilos de vida na contemporaneidade. São Paulo: Senac, p. 247-257.

Wallerstein, Immanuel. (I974-20II). The Modern World-System. Berkeley: California UP.

Wilson, Neil Housman \& Adams, Julia. (2015) Verbete "Historical Sociology". In: Wright, James D. (ed.). International Encyclopedia of the Social \& Behavioral Sciences, v. II, 2 ed. Amsterdam: Elsevier, p. 27-30. 


\section{CADA UM POR SI E NENHUM POR TODOS. ELEMENTOS DA COVARIAÇÃO NOS DOMÍNIOS DE ESTRUTURA SOCIAL E SEMÂNTICA \\ Resumo}

Apresenta-se o projeto luhmaniano de atualização sociológica pela perspectiva de seus estudos sobre a covariação de estrutura social e semântica. Evidencia-se a importância dessa questão no desenho da teoria dos sistemas e destaca-se a relevância dos estudos de Luhmann a respeito. Com isso, espera-se chamar a atenção para vertente menos reconhecida da moderna teoria dos sistemas, assim como oferecer outra via de acesso a seus desenvolvimentos.

\section{EVERYONE FOR THEMSELVES AND NONE FOR ALL. ELEMENTS OF COVARIATION IN THE DOMAIN OF SOCIAL STRUCTURE AND SEMANTICS}

Abstract

This article presents the Luhmannian project of updating social theory from the viewpoint of his studies of the covariation of social structure and semantics. It demonstrates the significance of this issue in the design of systems theory and highlights the relevance of Luhmann's studies of the topic. The aim is to draw attention to a less recognized aspect of modern systems theory, as well as to offer another way of exploring its developments.
Palavras-chave

Semântica social;

diferenciação social; teoria dos sistemas;

Luhmann.

Keywords

Social semantics;

social differentiation;

systems theory;

Luhmann. 